\title{
Prevalence of Acinetobacter Spp. Isolated from Clinical Samples Referred to Al-Kafeel Hospital and Their Antibiotic Susceptibility Patterns from 2017-2021
}

\author{
Suhad Hadi Mohammed ${ }^{1 *}$, Mohanad Mohsen Ahmed ${ }^{2}$, Narjes Abd Alameer Abd Alredaa ${ }^{1}$, \\ Huda Haider Abd Alabbas ${ }^{1}$, Zainab Dheyaa Mohammad Ali ${ }^{1}$, Zahraa Zuher Abed Al-Wahab ${ }^{1}$, \\ Zainab Ali Mohsin ${ }^{1}$, Zahraa Jalil Jasim Mohammed ${ }^{1}$, Zahraa Abd Al_Hamza Mohammed ${ }^{1}$, \\ Noor Yahya Abid Zaid ${ }^{1}$
}

1. Department of Clinical Laboratories, College of Applied Medical Sciences, Kerbala University, Kerbala, Iraq

2. Department of Microbiology, College of Medicine, Kerbala University, Kerbala, Iraq

\begin{abstract}
Background and Aim: Acinetobacter has been considered an important nosocomial pathogen since 1970. This study aims to investigate the prevalence of Acinetobacter infection during 2017-2021, study the antibiogram of these bacteria, and study the impact of gender on infection.
\end{abstract}

Materials and Methods: This is a retrospective study in which data of the clinical samples received in Al-Kafeel Hospital, Kerbala, Iraq, between April 2017 and February 2021 were searched for Acinetobacter infection and their antibiotic susceptibility testing.

Results: The prevalence of Acinetobacter infection was $9.2 \%$ of cases. Male to Female ratio was 3:1, and there was a significant difference in Acinetobacter infection regarding gender. There were high resistance rates to major antibiotic classes. Maximum resistance was recorded for Amoxicillin (100\%), followed by $3^{\text {rd }}$ generation cephalosporins, including Cefotaxime (92.3\%), Ceftriaxone (91.6\%), Ceftazidime (91.3\%), Cefixime (80\%); in addition to growing resistance to carbapenems, Imipenem (42.8\%) and Meropenem (62.2\%). The lowest resistance rates were found to colistin sulfate (10\%). There $80.7 \%$ of the isolates were multidrug-resistant MDR.

Conclusion: Acinetobacter spp., is considered as fast emerging opportunistic agents with evolving drug resistance. Rationale use of antibiotics is important and necessary to prevent microbial resistance. Gender is considered a risk factor for Acinetobacter infection.

Keywords: Acinetobacter spp., Antibiotic Susceptibility testing, Sex differences, MDR

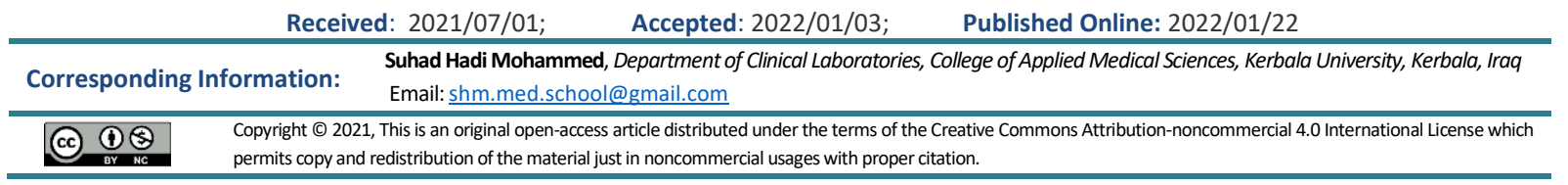

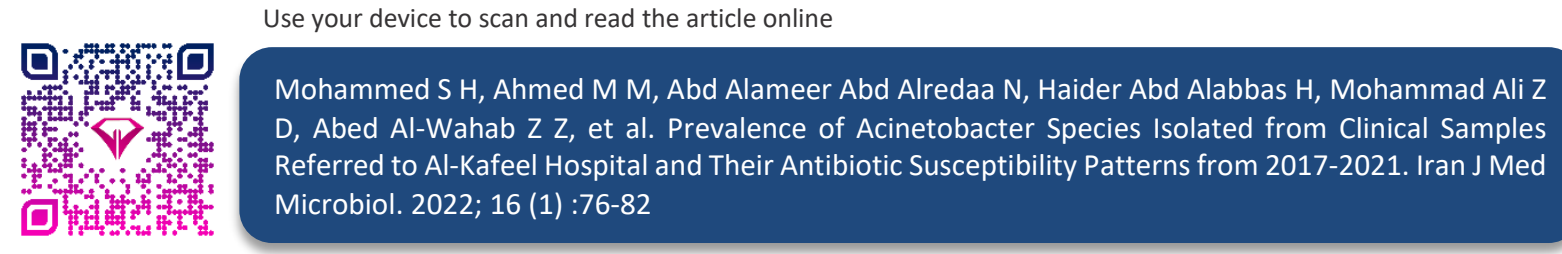

Download citation: BibTeX | RIS | EndNote | Medlars | ProCite | Reference Manager | RefWorks | Send citation to: $\otimes_{\text {Mendeley }} \mathbf{Z}_{\underline{\text { Zotero }}} \mathbb{H}_{\text {RefWorks }}$

\section{Introduction}

Acinetobacter is a highly diverse genus ubiquitous in the environment $(1,2)$ and has been considered a significant nosocomial pathogen since 1970 as it can survive in the hospital environment (on both dry and moist surfaces) (3-5). Subsequently, the bacteria are transmitted to patients either from environmental surfaces or from the hands of health care workers that were colonized transiently by these bacteria $(6,7)$.

The Greek word "akinetos" is the name Acinetobacter's origin meaning "unable to move". The term was chosen for the bacteria as they are not motile while displaying a twitching kind of motility (8). The genus 
belongs to the family Moraxellaceae and comprises Gram-negative, non-motile, oxidase-negative, glucose non-fermenting, strictly aerobic, catalase-positive bacteria (9).

Although there are more than 50 species within the Acinetobacter genus 2, most species are nonpathogenic. The most common species to cause infections is Acinetobacter baumannii (responsible for $90 \%$ of human infections caused by this genus and responsible for $17 \%$ of all nosocomial infections, especially amongst immunocompromised individuals), followed by Acinetobacter calcoaceticus and Acinetobacter Iwoffii (10-12).

Human infections caused by Acinetobacter species include community-acquired infections and hospitalacquired infections, especially in critically ill patients with impaired host defenses. These infections include pneumonia, endocarditis, meningitis, skin and wound infections, peritonitis in patients receiving peritoneal dialysis, UTI, and bacteremia $(13,14)$.

There were several reasons that made this genus receive significant attention. First, this genus causes nosocomial infections. Second is the emergence of the multiresistant strains, some of which are Pan-Resistant to antibiotics, that suddenly cause an outbreak of infection involving several patients in a clinical unit. Third, some strains have the ability to produce verotoxins $(8,15)$.

Concerning susceptibility between females and males, differences have been reported dealing with vaccination, autoimmune diseases, and infectious diseases (16-19). According to various studies, there is a differential immune response to infectious diseases regarding gender (20-23). The innate immune response of females is typically more substantial on the topic of infection (18).

With respect to the Antibiotic susceptibility pattern of Acinetobacter, it has been documented that susceptibility patterns may vary widely according to geographical regions and even among different units of the same hospital at different time points. This variation makes it necessary to set periodic monitoring for these pathogens to accurately select a therapy $(23,24)$.

Thus the current study aims to study the prevalence of Acinetobacter isolated from clinical samples collected in Al-Kafeel Hospital (2017-2021) and study the antibiotic susceptibility patterns of these isolates, and moreover, to examine the gender-related differences in Acinetobacter infections.

\section{Methods}

Following the approval of this study from the Department of Clinical Laboratories/ College of Applied Medical Sciences/ Kerbala University, retrospective study designs were conducted from December 2020 to May 2021. During this period, data of the clinical samples received in Al-Kafeel Hospital laboratory from April 2017 to February 2021 were collected. Results that showed the isolation of Acinetobacter spp. with their antibiotic susceptibility testing were obtained. Antibiotic susceptibility testing was done using disc diffusion methods and interpreted using CLSI guidelines (25). Data were analyzed using SPSS 24 software (SPSS Inc., Chicago, III., USA).

\section{Results}

During the study period, results of 1784 reports for different clinical samples received in the laboratory of Al-Kafeel Hospital were collected. Out of 135 (7.5\%), samples were examined by direct methods (gram stain and Acid Fast stain), and 1649 were cultured on MacConkey and Blood agar as requested. After overnight incubation, no growth or growth of nonpathogenic bacteria (i.e., considered as culturenegative cases) was observed in 970 (58.8\%), while $111(6.2 \%)$ cases were cultured for the presence of Fungi. A total of 568 cases were reported to have bacterial isolates. Antibiotic susceptibility testing was performed using manual methods for the samples that revealed the presence of pathogenic bacteria in the culture plates (i.e., culture-positive cases). Culture-positive reports were searched for the isolation of Acinetobacter spp. A total of of 52 reports were documented the growth of Acinetobacter spp. (9.2\%) from culture-positive cases (Table 1 ). Acinetobacter species were found to be associated with increased mortality rates (26) due to their ability to infect healthy hosts and their propensity to develop resistance to the broad spectrum Antibiotics (27). Lower prevalence rates were reported by Al-Sehlawi et al., who documented a $6.8 \%$ of isolates to be identified as $A$. baumannii from clinical samples referred to three hospitals in Al-Najaf, Iraq (28). Another study in Kerbala, Iraq, reported higher incidence rates (29). While other studies have accounted for $12.9 \%$ (30), $4.8 \%$ (23), and $3.36 \%$ (24) of Acinetobacter isolates from total infected samples. The observed differences in prevalence rate might be due to variation in the study design, methodology, and study time. 
Table 1. Prevalence of infection with Acinetobacter species.

\begin{tabular}{ccc}
\hline Type of Bacteria & Frequency & Percent \\
\hline Acinetobacter & 52 & 9.2 \\
\hline Other types of Bacteria & 516 & 90.8 \\
\hline Total & 568 & 100 \\
\hline
\end{tabular}

Regarding sex, 13 reports for clinical samples were taken from females, and 39 for males, and M/ F ratio was $3 / 1$. There was a significant association between infections with Acinetobacter spp. and sex, as shown in Table 2. Similarly, previous studies documented that Acinetobacter infection was more prevalent in males $(32,33)$. This may be due to male and female differences in immunological responses. In general, stronger innate and adaptive immune responses are reported regarding adult females compared with males.
Sex differences are visible in different species. Exposure to a wide range of stimuli (including bacteria, viruses, parasites, fungi, and vascular trauma) can severely reduce tissue function or lead to its loss in women compared to men $(18,20)$. Men were less compliant than females to hand-hygiene recommendations which made them more prone to infection (34). Furthermore, men were more likely to be affected by hospital-acquired infections $(35,36)$, which may be caused by higher hospitalization rates, especially in older age groups.

Table 2. Distribution of infection with Acinetobacter species among gender

\begin{tabular}{|ccccc|}
\hline \multirow{2}{*}{ Type of Bacteria } & \multicolumn{2}{c}{ Gender } & Total \\
\cline { 2 - 5 } & Female & Male & 52 \\
\hline Acinetobacter spp. & 13 & 39 & 516 \\
\hline Other types of Bacteria & 195 & 321 & 568 \\
\hline Total & 208 & 360 & \\
\hline
\end{tabular}

Concerning the clinical samples, Acinetobacter was isolated from swabs (24) followed by urine samples (8). There was no significant association between the type of sample and Acinetobacter infection, Table 3. In other previous studies, Acinetobacter isolation was predominating in urine $(21-27 \%)$ and tracheobronchial secretions (24.8, 48.8\%, respectively) (30).
Another study reported the predominant isolation of Acinetobacter from blood (36.9\%) followed by Pus (22.55), respiratory samples (14.4\%), urine (11.7\%), and other body fluids (9\%). An increase in Acinetobacter occurrence in blood cultures is reported in some hospital departments $(24,31)$.

Table 3. Association of infection with Acinetobacter and type of clinical sample

\begin{tabular}{|c|c|c|c|c|c|c|c|}
\hline \multirow[b]{2}{*}{ Type of Bacteria } & \multicolumn{6}{|c|}{ Sample type } & \multirow[b]{2}{*}{ Tota } \\
\hline & Blood & Fluid & Sputum & Swab & Urine & $\begin{array}{c}\text { Other } \\
\text { samples }\end{array}$ & \\
\hline $\begin{array}{c}\text { Acinetobacter } \\
\text { spp. }\end{array}$ & 5 & 7 & 4 & 24 & 8 & 4 & 52 \\
\hline $\begin{array}{l}\text { Other types of } \\
\text { Bacteria }\end{array}$ & 84 & 66 & 30 & 198 & 111 & 27 & 516 \\
\hline Total & 89 & 73 & 34 & 222 & 119 & 31 & 568 \\
\hline P-value & & & & 0.588 & & & \\
\hline
\end{tabular}

The frequency of Acinetobacter isolation during the years in the current study revealed a high frequency of isolation in 2020 (53.8\%) in comparison to other years, Table 4 . This might reflect the increase in the incidence of Acinetobacter infection due to its colonization and survival features (37). 
Table 4. Distribution of Acinetobacter infection during 2017-2021

\begin{tabular}{|cc|}
\hline Year & Frequency (Percentage) \\
\hline 2017 & $3(5.8)$ \\
2018 & $4(7.7)$ \\
2019 & $9(17.3)$ \\
2020 & $28(53.8)$ \\
\hline 2021 & $5(9.6)$ \\
\hline Total & $49(94.2)$ \\
\hline
\end{tabular}

\section{Antibiotic Susceptibility Patterns}

The susceptibility testing for the isolated Acinetobacter showed high rates of resistance to most antibiotics used. Maximum resistance was recorded for Amoxicillin (100\%), followed by $3^{\text {rd }}$ generation cephalosporins, including Cefotaxime (92.3\%), Ceftriaxone (91.6\%), Ceftazidime (91.3\%), and Cefixime (80\%). There was growing resistance to carbapenems, Imipenem (42.8\%), and Meropenem (62.2\%). The lowest resistance rates were found to colistin sulfate (10\%) (Table 5).

On the report of the World Health Organization (WHO) published in 2017, there was an urgent need for new antibiotics for 12 pathogens called the ESKAPE (ESKAPE is the acronym for the group of bacteria that include Enterococcus faecium, Staphylococcus aureus, Klebsiella pneumoniae, A. baumannii, Pseudomonas aeruginosa, and Enterobacter spp.) $(38,39)$.

Showing an increasing resistance to $\beta$-lactams aminoglycoside antibiotics, Acinetobacter has been considered a reservoir of antibiotic-resistant genes in a hospital environment (40). This is confirmed by our results which showed high resistance rates to most antibiotics used. The high resistance rates recorded in the current study are likely to be associated with a wide range of empirical and therapeutic use of antibiotics at hospitals. The employed selective pressure by this results in MDR strains emerging, which in turn may have led to the genes encoding resistance mechanisms (41). Being exposed to certain antibiotics has an advantage to a few resistant organisms in patients already colonized. It makes them become pathogens at the first opportunity (40).

Of the isolates, 42 (80.7\%) were MDR isolates (resistant to at least one antibiotic in three or more classes of Antibiotics: Penicillin, Cephalosporin, Aminoglycoside, Fluoroquinolone, Carbapenem. Gupta et al. reported that $39.6 \%$ of isolates were MDR (24). Higher rates of MDR A. baumannii isolates were reported by Yadav et al. (32). Whereas, in the study by Al-Sehlawi et al., $50 \%$ of the isolates were resistant to major antibiotic classes (28). Apparently, Acinetobacter tends to develop antibiotic resistance quickly. This might be due to its long-term evolutionary exposure to antibiotic-producing organisms in the soil environment (42). Facilitated by complex factors, the spread of resistance included mobile genetic elements, the misuse of antimicrobial drugs, poor infection control practices, and increased international travel (43).

Table 5. Antibiotic Susceptibility patterns among Acinetobacter spp. isolates

\begin{tabular}{|c|c|c|c|c|c|}
\hline Antibiotic & Antibiotic Class & $\begin{array}{c}\text { Number of tested } \\
\text { isolates }\end{array}$ & R (\%) & I (\%) & $\mathrm{S}(\%)$ \\
\hline Cefotaxime $(30 \mu \mathrm{g})$ & $\begin{array}{l}3^{\text {rd }} \text { generation } \\
\text { Cephalosporins }\end{array}$ & 39 & $36(92.3)$ & - & $3(7.6)$ \\
\hline Ceftriaxone $(30 \mu \mathrm{g})$ & $\begin{array}{l}3^{\text {rd }} \text { generation } \\
\text { Cephalosporins }\end{array}$ & 48 & $44(91.6)$ & - & $4(8.3)$ \\
\hline Ceftazidime (30 $\mu \mathrm{g})$ & $\begin{array}{l}3^{\text {rd }} \text { generation } \\
\text { Cephalosporins }\end{array}$ & 46 & $42(91.3)$ & $2(4.3)$ & $2(4.3)$ \\
\hline Cefixime $(10 \mu \mathrm{g})$ & $\begin{array}{l}\text { 3rd generation } \\
\text { Cephalosporins }\end{array}$ & 21 & 17 (80.9) & $1(4.7)$ & $3(14.2)$ \\
\hline Ciprofloxacin (5 $\mu \mathrm{g})$ & fluoroquinolones & 52 & $38(73.0)$ & $4(7.6)$ & $10(19.2)$ \\
\hline Levofloxacin (5 $\mu \mathrm{g})$ & fluoroquinolones & 51 & $13(25.4)$ & $18(35.2)$ & $20(39.2)$ \\
\hline Gentamicin (30 $\mu \mathrm{g})$ & Aminoglycoside & 51 & $34(66.6)$ & $1(1.9)$ & $16(31.3)$ \\
\hline Amikacin $(30 \mu \mathrm{g})$ & Aminoglycoside & 50 & $37(74)$ & $2(4)$ & $11(22)$ \\
\hline
\end{tabular}




\begin{tabular}{|c|c|c|c|c|c|}
\hline Antibiotic & Antibiotic Class & $\begin{array}{c}\text { Number of tested } \\
\text { isolates }\end{array}$ & R (\%) & I (\%) & S (\%) \\
\hline Tetracycline (30 $\mu \mathrm{g})$ & Tetracyclines & 45 & $28(62.2)$ & $1(2.2)$ & $16(35.5)$ \\
\hline Imipenem (10 $\mu \mathrm{g})$ & Carbapenems & 49 & $21(42.8)$ & $6(12.2)$ & $22(44.8)$ \\
\hline Meropenem (10 $\mu \mathrm{g})$ & Carbapenems & 44 & $27(61.3)$ & $3(6.8)$ & $14(31.8)$ \\
\hline Amoxicillin $(25 \mu \mathrm{g})$ & $\begin{array}{l}\text { Penicillin-like } \\
\text { antibiotics }\end{array}$ & 7 & $7(100)$ & - & - \\
\hline Trimethoprim (5 $\mu \mathrm{g})$ & Others & 37 & $27(72.9)$ & $5(13.5)$ & $5(13.5)$ \\
\hline $\begin{array}{l}\text { PipracillinTazobactam } \\
(110 \mu \mathrm{g})\end{array}$ & $\begin{array}{l}\text { Beta lactam -Beta } \\
\text { lactamase inhibitors }\end{array}$ & 27 & $17(62.9)$ & $4(14.8)$ & $6(22.2)$ \\
\hline $\begin{array}{l}\text { Colistin sulfate (10 } \\
\mu \mathrm{g})\end{array}$ & Polymyxin & 10 & $1(10.0)$ & $2(20.0)$ & $7(70.0)$ \\
\hline Cefipeme (30 $\mu \mathrm{g})$ & $\begin{array}{l}\text { Cephalosporin } \\
\text { antibiotic }\end{array}$ & 20 & $13(65.0)$ & $1(5.0)$ & $6(30.0)$ \\
\hline
\end{tabular}

\section{Conclusion}

Acinetobacter is an important opportunistic and emerging pathogen that can lead to severe infections. Spreading easily in the environment, these organisms infect or colonize patients and are able to persist in that environment for several days, a factor that might explain their tendency to cause extended outbreaks.

This study reported a high rate of antibiotic resistance by Acinetobacter isolates, indicating that new antibiotic using standards are better to be set in health centers to prevent the occurrence of bacteria resistance. Thus, to prevent microbial resistance, rational use of antibiotics is essential and new protocols are needed.

\section{References}

1. Ayobami O, Willrich N, Suwono B, Eckmanns T, Markwart R. The epidemiology of carbapenemnon-susceptible Acinetobacter species in Europe: analysis of EARS-Net data from 2013 to 2017. Antimicrob Resist Infect Control [Internet]. 2020;9(1):89. Available from: [DOI:10.1186/s13756-020-00750-5] [PMID] [PMCID]

2. Atrouni $A$ Al, Joly-Guillou $M L$, Hamze $M$, Kempf M. Reservoirs of non-baumannii Acinetobacter species. Front Microbiol. 2016;7(FEB):1-12. [DOI:10.3389/fmicb.2016.00049] [PMID] [PMCID]

3. Shamsizadeh Z, Nikaeen $M$, Esfahani BN, Mirhoseini SH, Hatamzadeh M, Hassanzadeh A. Detection of antibiotic resistant Acinetobacter baumannii in various hospital environments: potential sources for transmission of Acinetobacter infections. Environ Health Prev Med. 2017;22(1):1-7. [DOI:10.1186/s12199-0170653-4] [PMID] [PMCID]
Awareness is needed to control the environment, and tasks such as equipment decontamination and strict attention to hand washing should be undertaken to prevent the spread of Acinetobacter in hospitals.

\section{Acknowledgment}

We would like to express our appreciation to AlKafeel Hospital, Kerbala, Iraq, for providing the current study's data

\section{Conflict of Interest}

The authors declared no conflict of interest.

4. Forster DH, Daschner FD. Acinetobacter species as nosocomial pathogens. Eur J Clin Microbiol Infect Dis. 1998;17(2):73-7. s100960050020 [DOI:10.1007/s100960050020]

5. Abdulzahra AT, Khalil MAF, Elkhatib WF. First report of colistin resistance among carbapenemresistant Acinetobacter baumannii isolates recovered from hospitalized patients in Egypt. New microbes new Infect. 2018;26:53-8. [DOI:10.1016/j.nmni.2018.08.007] [PMID] [PMCID]

6. McDonald LC, Banerjee SN, Jarvis WR, System NNIS. Seasonal variation of Acinetobacter infections: 1987-1996. Clin Infect Dis. 1999;29(5):1133-7. [DOI:10.1086/313441] [PMID]

7. Spellberg B, Bonomo RA. "Airborne assault": a new dimension in Acinetobacter baumannii transmission. Crit Care Med. 2013;41(8). [DOI:10.1097/CCM.0b013e31829136c3] [PMID] [PMCID] 
8. Doughari HJ, Ndakidemi PA, Human IS, Benade S. The ecology, biology and pathogenesis of Acinetobacter spp.: an overview. Microbes Environ. 2009;1103150282.

9. Rossau R, Van Landschoot A, Gillis M, De Ley J. Taxonomy of Moraxellaceae fam. nov., a new bacterial family to accommodate the genera Moraxella, Acinetobacter, and Psychrobacter and related organisms. Int J Syst Evol Microbiol. 1991;41(2):310-9. [DOI:10.1099/00207713-41-2310]

10. Dijkshoorn L, van der Toorn J. Acinetobacter species: which do we mean? Clin Infect Dis. 1992;15(4):748-9. [DOI:10.1093/clind/15.4.748] [PMID]

11. Visca P, Seifert H, Towner KJ. Acinetobacter infection - An emerging threat to human health. IUBMB Life. 2011;63(12):1048-54. [DOI:10.1002/ iub.534] [PMID]

12. Munier $A-L$, Biard $L$, Legrand $M$, Rousseau $C$, Lafaurie $M$, Donay J-L, et al. Incidence, risk factors and outcome of multi-drug resistant Acinetobacter baumannii nosocomial infections during an outbreak in a burn unit. Int J Infect Dis. 2019;79:179-84.

[DOI:10.1016/j.ijid.2018.11.371] [PMID]

13. Oberoi A, Aggarwal A, Lal M. A Decade of an Underestimated Nosocomal PathogenAcinetobacter In a Tertiary Care Hospital in Punjab. JK Sci. 2009;11(1).

14. Dijkshoorn L, Nemec A, Seifert H. An increasing threat in hospitals: multidrug-resistant Acinetobacter baumannii. Nat Rev Microbiol. 2007;5(12):939-51. [DOl:10.1038/nrmicro1789] [PMID]

15. Grupper M, Sprecher $H$, Mashiach $T$, Finkelstein R. Attributable mortality of nosocomial Acinetobacter bacteremia. Infect Control Hosp Epidemiol. 2007;28(3):293-8. [DOl:10.1086/512629] [PMID]

16. Klein SL, Jedlicka A, Pekosz $A$. The $X$ s and $Y$ of immune responses to viral vaccines. Lancet Infect Dis. 2010;10(5):338-49. [DOI:10.1016/S1473-3099(10)70049-9]

17. Dunn SE, Ousman SS, Sobel RA, Zuniga L, Baranzini SE, Youssef $S$, et al. Correction: Peroxisome proliferator-activated receptor (PPAR) $\alpha$ expression in T cells mediates gender differences in development of $T$ cell-mediated autoimmunity. J Exp Med. 2018;215(6):1765. [DOI:10.1084/jem.2006183905142018c] [PMID] [PMCID]
18. Klein SL, Flanagan KL. Sex differences in immune responses. Nat Rev Immunol. 2016;16(10):62638. [DOI:10.1038/nri.2016.90] [PMID]

19. Voskuhl R. Sex differences in autoimmune diseases. Biol Sex Differ. 2011;2(1):1-21. [DOI:10.1186/2042-6410-2-1] [PMID] [PMCID]

20. Scotland RS, Stables MJ, Madalli S, Watson P, Gilroy DW. Sex differences in resident immune cell phenotype underlie more efficient acute inflammatory responses in female mice. Blood, J Am Soc Hematol. 2011;118(22):5918-27. [DOI:10.1182/blood-2011-03-340281] [PMID] [PMCID]

21. Abid S, Xie S, Bose M, Shaul PW, Terada LS, Brody $S L$, et al. 17 $\beta$-estradiol dysregulates innate immune responses to Pseudomonas aeruginosa respiratory infection and is modulated by estrogen receptor antagonism. Infect Immun. 2017;85(10):e00422-17.

[DOI:10.1128/IAI.00422-17] [PMID] [PMCID]

22. Vermillion MS, Ursin RL, Attreed SE, Klein SL. Estriol reduces pulmonary immune cell recruitment and inflammation to protect female mice from severe influenza. Endocrinology. 2018;159(9):3306-20. [DOl:10.1210/en.201800486] [PMID] [PMCID]

23. Lone R, Shah A, Kadri SM, Lone S, Faisal S. Nosocomial multi-drug-resistant Acinetobacter infections-clinical findings, risk factors and demographic characteristics. Bangladesh J Med Microbiol. 2009;3(1):34-8.

[DOI:10.3329/bjmm.v3i1.2969]

24. Gupta N, Gandham N, Jadhav S, Mishra RN. Isolation and identification of Acinetobacter species with special reference to antibiotic resistance. J Nat Sci Biol Med. 2015;6(1):159-62. [DOI:10.4103/0976-9668.149116] [PMID] [PMCID]

25. Bhattacharyya S, Bhattacharyya I, Rit K, Mukhopadhyay PK, Dey JB, Ganguly U, et al. Antibiogram of Acinetobacter spp. isolated from various clinical specimens in a tertiary care hospital in West Bengal, India. Biomed Res. 2013;24(1).

26. Jain $A L$, Harding $C M$, Assani $K$, Shrestha $C L$, Haga $M$, Leber $A$, et al. Characteristics of invasive Acinetobacter species isolates recovered in a pediatric academic center. BMC Infect Dis. 2016;16(1):1-9. [DOI:10.1186/s12879-016-16789] [PMID] [PMCID]

27. Poirel L, Bonnin RA, Nordmann P. Genetic basis of antibiotic resistance in pathogenic 
Acinetobacter species. IUBMB Life. 2011;63(12):1061-7. [DOI:10.1002/iub.532] [PMID]

28. Sadiq Z, Sehlawi A. Isolation and Identification of Acinetobacter baumannii Clinical Isolates using Novel Methods. J Babylon Univ. 2014;22(3).

29. AL-Baroody HN, Al-Ghanimi AAK. Isolation and Identification of Nosocomial Pathogen Acinetobacter baumannii From Al-Hussien Medical City in Karbala. Sci J Med Res. 2020;4(14):54-9.

30. Lahiri KK, Mani NS, Purai SS. Acinetobacter spp as nosocomial pathogen: Clinical significance and antimicrobial sensitivity. Med J Armed Forces India. 2004;60(1):7-10. [DOI:10.1016/S03771237(04)80148-5]

31. Hejnar $P$, Kolář $M$, Hájek V. Characteristics of Acinetobacter strains (phenotype classification, antibiotic susceptibility and production of sslactamases) isolated from haemocultures from patients at the Teaching Hospital in Olomouc. Biomed Pap. 1999;

32. Yadav SK, Bhujel R, Hamal P, Mishra SK, Sharma $S$, Sherchand JB. Burden of multidrug-resistant Acinetobacter baumannii infection in hospitalized patients in a tertiary care hospital of Nepal. Infect Drug Resist. 2020;13:725-32. [DOI:10.2147/IDR.S239514] [PMID] [PMCID]

33. Patel RV, Shah JS, Revathi G, Siika W, Shah R. Acinetobacter infections: a retrospective study to determine inhospital mortality rate and clinical factors associated with mortality. Infect Prev Pract [Internet]. 2019;1(2):100010. Available from: [DOI:10.1016/i.infpip.2019.100010] [PMID] [PMCID]

34. Humphreys H, Fitzpatick F, Harvey BJ. Gender differences in rates of carriage and bloodstream infection caused by methicillin-resistant Staphylococcus aureus: are they real, do they matter and why? Clin Infect Dis. 2015;61 (11):1708-14. [DOI:10.1093/cid/civ576] [PMID]

35. Vincent J-L, Sakr Y, Singer M, Martin-Loeches I, Machado FR, Marshall JC, et al. Prevalence and outcomes of infection among patients in intensive care units in 2017. Jama. 2020;323 (15):1478-87. [DOl:10.1001/jama.2020.2717] [PMID] [PMCID]
36. Neubeiser A, Bonsignore M, Tafelski S, Alefelder C, Schwegmann K, Rüden $\mathrm{H}$, et al. Mortality attributable to hospital acquired infections with multidrug-resistant bacteria in a large group of German hospitals. J Infect Public Health. 2020; 13(2):204-10. [DOI:10.1016/j.jiph.2019.07.025] [PMID]

37. Eliopoulos GM, Maragakis LL, Perl TM. Acinetobacter baumannii: epidemiology, antimicrobial resistance, and treatment options. Clin Infect Dis. 2008;46(8):1254-63. [DOI:10.1086/529198] [PMID]

38. Mulani MS, Kamble EE, Kumkar SN, Tawre MS, Pardesi KR. Emerging strategies to combat ESKAPE pathogens in the era of antimicrobial resistance: a review. Front Microbiol. 2019; 10:539. [DOI:10.3389/fmicb.2019.00539] [PMID] [PMCID]

39. Blanco N, Harris AD, Rock C, Johnson JK, Pineles L, Bonomo RA, et al. Risk factors and outcomes associated with multidrug-resistant Acinetobacter baumannii upon intensive care unit admission. Antimicrob Agents Chemother. 2018;62(1): e01631-17. [DOI:10.1128/AAC.01631-17]

40. Kong BH, Hanifah YA, Yusof MYM, Thong KL. Antimicrobial susceptibility profiling and genomic diversity of multidrug-resistant Acinetobacter baumannii isolates from a teaching hospital in Malaysia. Jpn J Infect Dis. 2011;64(4):337-40.

41. Perez F, Hujer AM, Hujer KM, Decker BK, Rather PN, Bonomo RA. Global challenge of multidrugresistant Acinetobacter baumannii. Antimicrob Agents Chemother. 2007;51(10):3471-84. [DOI:10.1128/AAC.01464-06] [PMID] [PMCID]

42. Manchanda V, Sanchaita S, Singh NP. Multidrug resistant acinetobacter. J Glob Infect Dis. 2010;2(3):291. [DOI:10.4103/0974-777X.68538] [PMID] [PMCID]

43. Ahmed MU, Farooq R, Al Hawashim N, Ahmed M, Yiannakou N, Sayeed F, et al. Sensitive, resistant and multi-drug resistant Acinetobacter baumanii at Saudi Arabia hospital eastern region. Pak J Pharm Sci. 2015;28(3). 